\title{
An Isolated Cumulus Cloud Modification Project
}

\author{
A. I. Weinstein and P. B. MacCready, Jr. \\ Meteorology Research, Inc., Alladena, Calif. \\ (Manuscript received 7 July 1969, in revised form 8 September 1969)
}

\begin{abstract}
A randomized seeding experiment was conducted in Flagstaff, Ariz., in July and August of 1967 wherein the heights, rainfall amounts and rainfall durations of isolated cumuli were measured. Twenty-one clouds were studied, 10 seeded and 11 not seeded, on 11 days. On nine days there were paired seed and no-seed events. The choice of the test clouds and much of the analysis was performed with the aid of a simple numerical model of cumulus dynamics and microphysics. The project aims were to show distinct effects of seeding on cloud-top height, rainfall and duration; to verify and/or improve the model; and to use the model to interpret the importance of the seeding effect.

For the 21 test clouds, the average increases in radar tops, precipitation and duration were $5900 \mathrm{ft}, 2.00$ $\mathrm{mm}$ and $10 \mathrm{~min}$, respectively, with student's $t$-test significance values being 96,92 and $81 \%$, respectively. On the nine days of paired seed and no-seed events, the $t$-test significance exceeded $98 \%$ for the three variables quoted above. On every one of the nine days, the seeded clouds showed increased height, rainfall and duration.

Using the model after it was calibrated against the 11 control clouds, it was found that the seeding increased the 10 cloud-top heights by an average of $6000 \mathrm{ft}$, with a maximum of $21,500 \mathrm{ft}$. The student $t$-test significance value for this increase was $96 \%$.

Using the calibrated model on all of the 21 test clouds showed how much benefit could have been derived from seeding all of the clouds. The average potential increase in cloud-top height was $6500 \mathrm{ft}$. This represents a $52 \%$ increase assuming bases at $13,000 \mathrm{ft}$. Comparison with observations showed an rms prediction error of $3341 \mathrm{ft}$. The corresponding rainfall and duration increases were $+2.86 \mathrm{~mm}$ (up from $2.99 \mathrm{~mm}$ ) and $7 \mathrm{~min}$ (up from $11 \mathrm{~min}$ ), respectively. These hypothetical increases are comparable to the observed values.
\end{abstract}

\section{Introduction}

The initial concept behind early weather modification work in the late 1940's dealt with a microphysics effect, e.g., manipulating the colloidal stability of a supercooled cloud. Ice nuclei added to the cloud would serve as embryos for particles which would grow large enough by molecular diffusion and coalescence to fall out. This would serve to clear holes in supercooled fogs and stratus and to augment the development of precipitation from orographic and convective storms.

American and Australian experimenters in 1947 noted instances of rapid cloud growth after some seeding of cumulus clouds, and attributed the growth as being a consequence of the added buoyancy from the heat of fusion as supercooled water was converted to ice. The magnitude and overall importance of this dynamic effect from seeding was not fully appreciated until after Hosler et al. (1963) and Simpson et al. (1965) developed numerical models of cumulus growth and applied them to field experiments in Pennsylvania and the Caribbean.

In considering the relative importance of the roles of the microphysics effects of seceling and the dynamics effects, one must note that both maty be important and that they are intimately interconnected. If the natural environmental stability and moisture content is such that an unseeded cloud will not grow high enough to reach the natural glaciation temperature but will attain some warmer, and thus lower, artificial glaciation temperature, then seeding can make a distinct increase in the cloud development. If the region into which the cloud grows after artificial glaciation is unstable, this growth can be very large, and the cloud will thus process more total water and have a longer duration. Such a larger, longer-lasting, seeded cloud could be expected to yield considerably more rain than if it were unseeded, provided the seeding effects did not interfere greatly with the microphysics of the hydrometeor growth mechanism.

This program is aimed at demonstrating seeding effects on isolated cumulus clouds, using the help of a numerical model incorporating both microphysics and dynamics factors. The emphasis is on the dynamic effects, which are considered the most important in many of the selected test cases, are easiest to measure, and are easiest to predict with the simple model. Still, some attention is paid to the microphysics effects and the actual precipitation magnitulc.

The model serves as a help in selecting test clouds for which the dynamics effect is expected to be large. The model also serves to help with the evaluation of results. 
Observations, in turn, help with refining the model. The model is both a tool for evaluation and the subject of evaluation. The acceptance of a hypothesis as to the validity of seeding effects depends on a combination of factors: cloud selection, test randomization, pairing, the physical understanding of the microphysics and dynamics, the preexisting model and its modification, the observational setup, and the reasonableness of the whole procedure. We discuss these factors when presenting the numerical results so the reader can obtain the most accurate assessment of the validity of the results.

This program is based on 1) a field experiment wherein isolated clouds were selected and seeded or not on a random basis, and 2) a simple computer model which predicted three gross factors which could be measuredthe maximum height, the rainfall amount, and the rainfall duration. The seeding was performed in the same simple manner for each seeding case, i.e., from an airplane spiraling under the cloud base for $\sim 20 \mathrm{~min}$.

To give the program the maximum possible effectiveness, the clouds were carefully selected to fit in with the requirements of the limited model. The parameterized model included dynamics factors and microphysics terms. The basic inputs into the model are the environmental lapse rates of temperature and humidity, the updraft radius, the cloud base height, and an assumed temperature for natural and artificial glaciation. The model selection further requires the upcurrent strength to exceed a certain lower limit at the start of seeding, that the cloud be isolated, and that rain not be coming out of the base at the start of seeding. The selection process does not consider whether or not precipitation has already started to grow within the cloud. The basic design of the program was the product of L. G. Davis, who also acted as observer in the seeding aircraft.

On 11 project days, 21 clouds were studied -10 seeded and 11 not seeded. Nine days involved paired seededunseeded events. In this paper we try to derive as much information as possible from this small randomized data sample.

\section{Data collection procedure}

The principal reason for the inconclusive results obtained in many of the previous isolated cumuli seeding experiments was a poor choice of test clouds. Clouds which could not have possibly responded appreciably to seeding treatment were seeded along with those which could, and did, respond. When cloud top and precipitation increases for all of the clouds were combined, the negative, or no-increase, cases masked the favorable cases and the results were inconclusive.

A typical summer sounding in Flagstaff is characterized by a mid-level strongly stable layer whose base temperature is between -10 and $-20 \mathrm{C}$. Below this stable layer there is usually a dry, conditionally unstable zone. Above the strongly stable layer, the sounding is usually moist adiabatic or just barely stable up to the tropopause. The horizontal dimensions of cumuli growing into such a vertically stratified environment will control the clouds' growth. Small clouds will mix with the dry environment to a sufficient extent to cause these clouds to top out below the strong stable layer. Their cloud-top temperature will usually be greater than any potential artificial ice nucleation temperature. Large clouds will be sufficiently shielded from their environment to grow up through the stable cap into levels where the temperature is cold enough to lead to almost complete natural glaciation. Clouds with horizontal dimensions between the two extremes will be diluted enough by the dry environment to be stopped by the strong stable layer at a temperature somewhere between -8 and $-25 \mathrm{C}$.

The small and large cumuli are not suitable for treatment with artificial ice nuclei. In the first case, the clouds top out at a temperature which is too warm to activate the nuclei. In the second case, nature is supplying enough nuclei to realize most of the latent heat of fusion that is carried by the supercooled water in the cloud.

Intermediate size clouds should be used for testing, because artificial ice nuclei in these clouds can trigger freezing which would never have occurred naturally. The heat thus realized will enable the cloud to penetrate the strong stable layer and rise into the less stable zone above. In this way, the cloud's vertical extent, internal circulation, duration, and water-producing capabilities are increased.

In order to ensure that the correct sizes of clouds were chosen for the tests, a systematic series of six cloud calculations was performed on the morning sounding each day. The calculations were done by a fast-calculating numerical model developed for the project at the Pennsylvania State University. Three cloud sizes were used: $1.0,2.0$ and $3.0 \mathrm{~km}$ radii, each with two ice nucleation temperatures, $-8 \mathrm{C}$ (to simulate seeded clouds) and $-25 \mathrm{C}$ (to simulate natural clouds). The size of cloud shown to be potentially most responsive to seeding on each day was designated as the size of cloud to be used for the tests on that day if at all possible.

Upon designation of the correct size cloud, a seeding aircraft (Cessna 180) was dispatched to obtain an aircraft sounding. This sounding was taken to verify the general characteristics of the early morning sounding and to be used in the eventual detailed analysis of the results.

Upon completion of the sounding ( $\sim 30 \mathrm{~min})$, the observer aboard the C-180 reported to the ground controller that he was commencing a search for a cloud of the approximate size designated by the computer calculations as suitable for testing. At this time, the radar operator was instructed to start tracking the C-180 with one of the $3-\mathrm{cm}$ tracking sets of the Nike-Ajax radar used on the program. As the C-180 approached a suitable cloud, it made a preliminary pass at the cloud base. 
The observer communicated to the ground the points of entry and exit from under the cloud and these were noted on the $X-Y$ plot board in the radar. Sometimes the C-180 would also circle under the cloud edges to delineate the cloud size and position on the chart board more clearly. Since the seeding technique chosen for the experiment was airborne seeding with AgI-acetone burners on the wings of the aircraft, the seeding procedure required that the test cloud have a minimum updraft of $300 \mathrm{ft} \mathrm{min}^{-1}$ and that the seeding be performed while the aircraft spiraled below cloud base. The seeding was sometimes done as far as $1000 \mathrm{ft}$ below the base, but often with the Flagstaff clouds a higher altitude was required to keep the plane in a satisfactory upcurrent. The seeding was performed in this manner in order to ensure that the seeding material would get up into the active core of the cloud, and that the material would be dispersed adequately throughout the entire diameter of the core. To keep the number of variables down in this randomized study, all seeding was done this exact way, with the only variation being the use of either one or two generators. This seeding is not necessarily considered the optimum for producing rain, but we felt it would routinely demonstrate the maximum dynamic effects.

When it was ascertained that the cloud met the optimum requirements (size and updraft intensity), the cloud was designated as a "test" cloud. At this point, the radar operator was instructed to stop tracking the C-180 and commence vertical profiling of the cloud. The pilot of the C-180 then drew a card which said either "seed" or "control." He commenced spiraling in the updraft with the AgI generators either on or off, depending upon the card drawn. The cards had been previously set up on a random basis for the "seed" or "control" commands. The second test cloud for each day was treated as the opposite of the first cloud, in order to have a pair on each day and have both a "seed" and a "control" with comparable environments. The first test cloud of each day was, of course, always unbiased by any prior knowledge of whether or not it would be seeded. After 26 July the observer who made the choice of the cloud did not know of the "seed" or "control" command, nor could he see if the generators were turned on. Thus, his choice of the second cloud was completely unbiased. Prior to this date, the observer did know of the action on the first cloud. We feel his choice of the next cloud was still a fair one, but recognize that such a practice is not in accord with the strict requirements for randomization.

The seeding, or mock seeding, continued for $\sim 20 \mathrm{~min}$, or until it was obvious that the updraft had died. The radar profiling continued throughout the seeding period and for $\sim 1 \mathrm{hr}$ after. The profile data were recorded on a CEC oscillograph recorder along with $X-Y$ position, slant range and height of the range gate, time marks, notes of the beginning and end of each profile, and height of the echo top on each profile. Observers on the ground, as well as the C-180 observer, took photographs of the test cloud and kept notes of visible cloud top, glaciation, initial 3- and 10-cm radar echoes, initial raindrops at seeding level and their size, lightning, and any other pertinent factors.

After the 20 -min seeding period, the C-180 climbed out above or beside the test cloud and the observer noted its growth. Approximately $40 \mathrm{~min}$ after the end of the seeding (or mock seeding), the C-180 observer commenced searching for a second cloud. Every effort was made to find a second cloud of the same size and updraft condition as the first. Upon finding a second cloud, the procedure of marking the cloud, radar profiling, seeding and observing was followed exactly as with the first cloud. The selection of suitable clouds is really quite difficult since the desire is for a certain size, in a certain stage of development, in an area fairly close to the radar, and (if possible) photographable from the control site.

In August (the program started on 18 July 1967), a second aircraft was added to the observation equipment. This aircraft, a supercharged Piper Aztec C, was instrumented with the standard meteorological instrument package, plus an aluminum foil impactor and an MRI Continuous Particle Collector. The instrumented aircraft made penetrations into test clouds concurrent with the seeding and radar profiling. The data collected by the instrumented aircraft will not be included here, but some of it appears in the Bureau of Reclamation report from which this paper is condensed.

Fig. 1 gives a diagram of the data collection procedure and a schematic of the $3-\mathrm{cm}$ radar data on the CEC chart record. Note that the vertical increment between successive radar penetrations was kept at approximately $1000 \mathrm{ft}$. One complete radar profile took 5-10 min, depending upon the depth of the cloud. Only the A-B segments of the profiling were performed until a $3-\mathrm{cm}$ radar echo was observed. The core of the test cloud is easily identified on the CEC chart record. Note the time marks across the top of the trace. Only the traces of radar return and range gate height are shown in the figure. Whenever both $3-\mathrm{cm}$ trackers of the Nike-Ajax radar system were operative, the second tracker was used to track for the C-180 continuously. The C-180 and the Aztec had L-band ATC beacons. Their positions, as well as any $10-\mathrm{cm}$ radar echoes, were displayed on the PPI scope of the Nike-Ajax system, and the scope was continuously photographed in $16-\mathrm{mm}$ time-lapse. A second 16-mm time-lapse camera was set up outside the radar trailer to photograph the cloud directly.

\section{The computer model}

The numerical model used for the cloud calculations was developed at The Pennsylvania State University. A complete description of the model is given by Weinstein and Davis (1968).

The model is a steady-state Lagrangian solution of the equations used by Davis (1965), along with the 


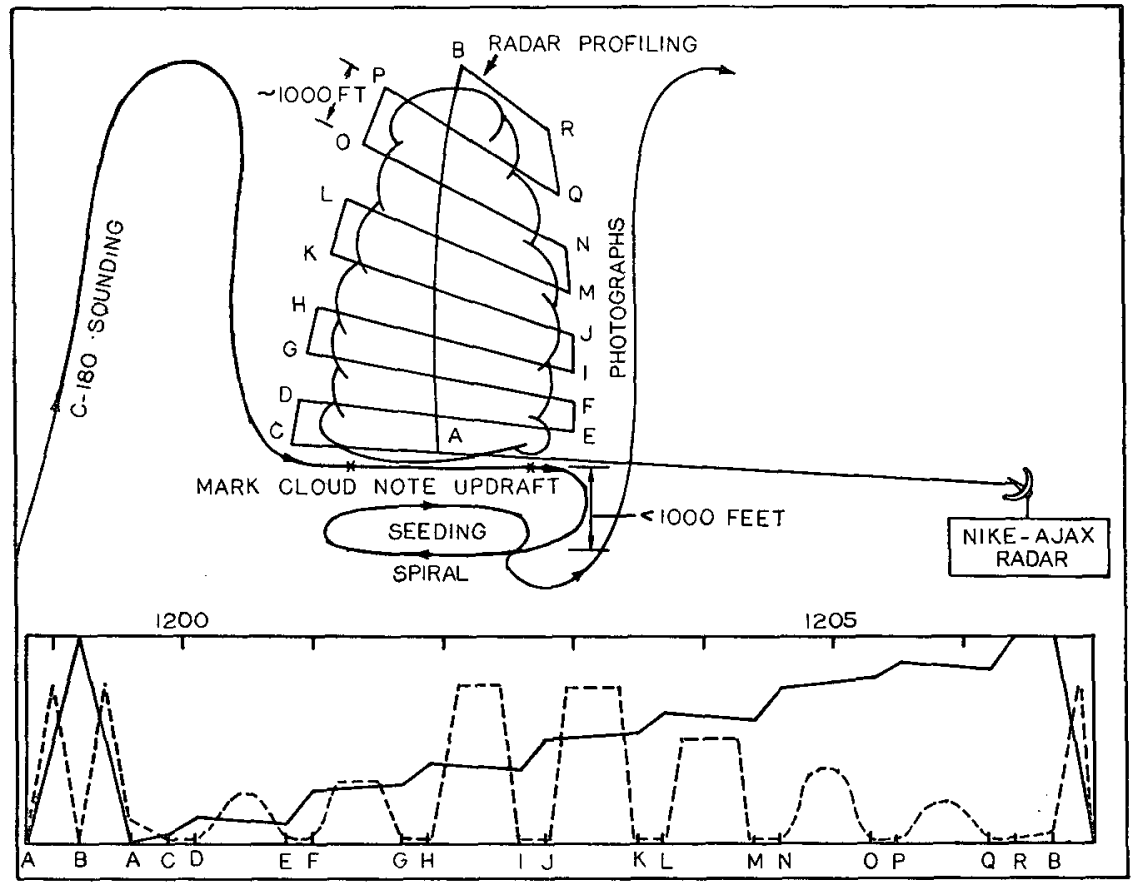

Fig. 1. Data collection procedure and schematic representation of the 3-cm radar data as it appeared on the CEC chart record. The solid trace on the CEC records is the height of the range gate, the dashed trace is the radar return.

cloud microphysics parameterization developed by Kessler et al. (1962-1964). The thermodynamic and dynamic calculations are numerical analogs of the classical parcel method with entrainment. The equations that are used are a version of the first law of thermodynamics and the vertical equation of motion. The entrainment concepts of Stommel (1947) are included in the calculations in a manner similar to that employed by Simpson et al. (1965).

The cloud microphysics calculations partition the liquid water in the updraft into cloud water $Q_{c}$ (liquid water contained in small droplets) and hydrometeor water $Q_{h}$ (liquid water contained in precipitation size drops). Cloud water is produced directly from condensation and is transformed into hydrometeor water via conversion and collection. Conversion, ( (conv, $_{\text {, is the }}$ process by which a few collisions between the many small droplets produce a few large drops. Since the probability of collision between small droplets is low, the conversion parameterization requires that there be some threshold cloud liquid water content present before conversion is allowed to operate. Conversion occurs at a parameterized rate $K_{1}$, on the excess cloud water above the threshold $A$, i.e.,

$$
\left(\frac{d Q_{h}}{d t}\right)_{\text {onv }}=-\left(\frac{d Q_{c}}{d t}\right)_{\text {conv }}=K_{1}\left(Q_{c}-A\right) .
$$

As soon as hydrometeors are formed, they assume some particular drop-size distribution and start falling relative to the updraft with the terminal velocity $V_{t}$ of the median volume drop diameter $D_{0}$ of the distribution. As the hydrometeors fall, they collect cloud water via the continuous collection process outlined by Langmuir (1948). The rate of collection and the form of the parameterized relationship describing it are functions of the drop-size distribution, the functional relationship between terminal velocity and drop size, and the collection efficiency $E$. Following Kessler et al. (1962-1964), the Marshall-Palmer drop-size distribution and a curve fit to Gunn and Kinzer's terminal velocity observations were used. These are as follows:

$$
N=N_{0} \exp (-\lambda D)
$$

where $N_{0}=10^{7} \mathrm{~m}^{-4}, D$ is drop diameter and $\lambda$ the spread of the drop size distribution; and

$$
V_{t}=-130 D_{0}^{0.5} \text {. }
$$

The rate of collection $K_{2}$ is given by

$$
K_{2}=6.96 \times 10^{-4} N_{0}^{0.125} E\left[\mathrm{sec}^{-1}\right] .
$$

The relationship for production of hydrometeor water via collection, ()$_{\text {coll }}$, is given by

$$
\left(\frac{d Q_{h}}{d t}\right)_{\text {ooll }}=-\left(\frac{d Q_{c}}{d t}\right)_{\text {ooll }}=K_{2} Q_{c} Q_{h}^{0.875}
$$

The complete set of equations solved on the model is as 


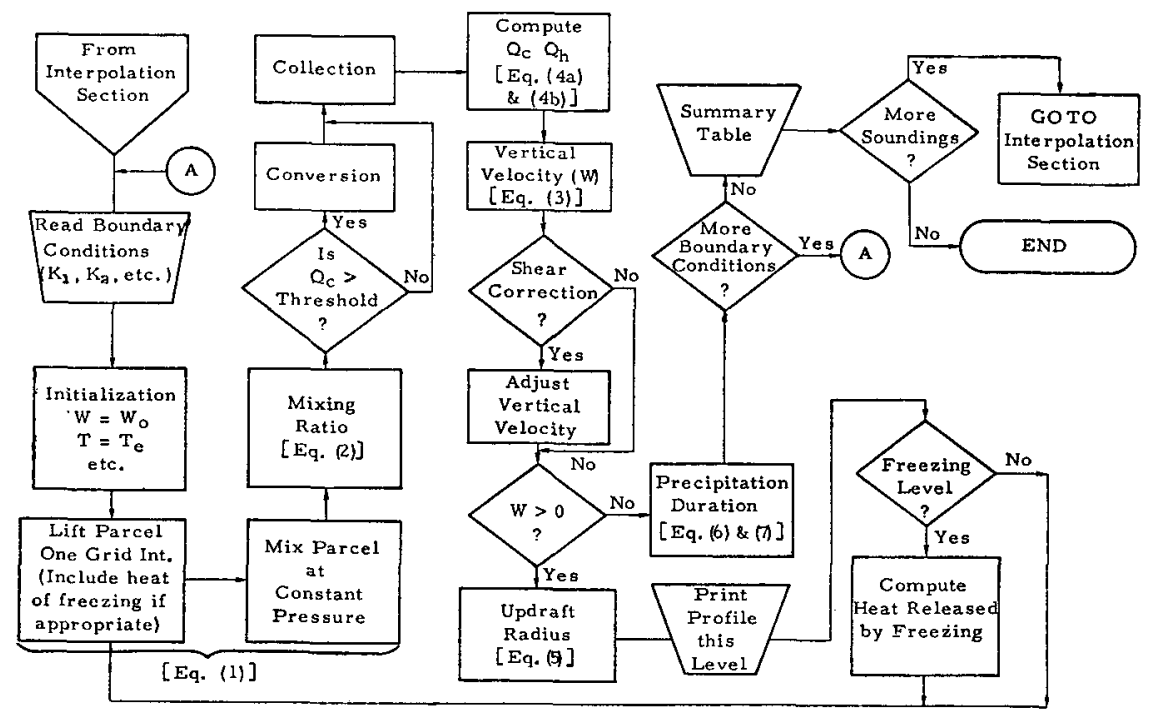

FIG. 2. Flow diagram for main calculation.

follows:

$$
\begin{aligned}
& \frac{d T}{d z}=\left[-\frac{g}{c_{p}}\left(1+\frac{L q_{s}}{R T}\right)-\mu\left(T-T_{e}\right)-\mu \frac{L}{c_{p}}\left(q-q_{e}\right)\right. \\
& \left.+\frac{L_{f} Q}{c_{p} d z}+\frac{L_{s}\left(\Delta q_{s}\right)_{w \rightarrow i}}{c_{p} d z}\right] /\left(1+\frac{\epsilon L^{2} q_{s}}{c_{p} R T^{2}}\right), \\
& q_{s}=\frac{\epsilon e_{s}}{p-e_{s}}, \quad \frac{1}{e_{8}} \frac{d e_{s}}{d T}=\frac{\epsilon L}{R T^{2}}, \\
& \frac{1}{2} \frac{d w^{2}}{d z}=g\left(\frac{T_{v}-T_{v e}}{T_{v e}}-Q\right)-\frac{\mu w^{2}}{2}, \\
& Q=Q_{c}+Q_{h}, \\
& \frac{d Q_{c}}{d z}=-\frac{d q_{s}}{d z}-\mu\left(q-q_{e}+Q_{c}\right)-\frac{K_{1}}{w}\left(Q_{c}-A\right) \\
& -\frac{K_{2}}{\left(w-V_{l}\right)} \rho^{-0.875} Q_{c} Q_{h}^{0.875}, \\
& \frac{d Q_{h}}{d z}=\frac{K_{1}}{w}\left(Q_{c}-A\right)+\frac{K_{2}}{\left(w-V_{t}\right)} \rho^{-0.875} Q_{c} Q_{h}{ }^{0.875}, \\
& V_{T}=-130 D_{0}^{0.5} \\
& D_{0}{ }^{0.5}=K_{3} Q_{h}^{0.125} \text {, where } K_{3}=f\left(N_{0}, \lambda\right) \text {, } \\
& \frac{d(\ln R)}{d z}=0.5\left[\frac{d(\ln w)}{d z}+\frac{d(\ln \rho)}{d z}\right]
\end{aligned}
$$

where all recognizable symbols have their standard meteorological meaning; in addition, $T_{v}$ is the virtual temperature, $T_{e}$ the environment temperature, $q_{e}$ the environment mixing ratio, $\mu$ the entrainment rate $=(1 / M) d M / d Z=C / R_{u}$, where $C$ is an empirical constant, $R_{u}$ the updraft radius (meters), $M$ mass, and $\left(\Delta q_{s}\right)_{w \rightarrow i}=q_{s}$ over water $-q_{s}$ over ice.

The total precipitation at cloud base is taken as the integral of the hydrometeor liquid water content over the depth of the cloud, i.e.,

$$
P=\int_{\text {base }}^{\text {top }} Q_{h} d Z
$$

The duration of precipitation at cloud base is taken as the difference in time between the arrival at cloud base of the hydrometeor from cloud base (zero) and the arrival from cloud top, or

$$
D=\frac{\text { cloud depth }}{V_{\iota} \text { top }} \text {. }
$$

A flow diagram of the main calculation section of the model is given in Fig. 2. The interpolation section of the program reduces a sounding of pressure $(\mathrm{mb})$, temperature $\left({ }^{\circ} \mathrm{C}\right)$, relative humidity $(\%)$, and horizontal wind speed $\left(\mathrm{m} \mathrm{sec}^{-1}\right)$, taken at irregular vertical points (i.e., mandatory and significant levels), to a sounding of pressure $(\mathrm{cb})$, temperature $\left({ }^{\circ} \mathrm{K}\right)$, mixing ratio $\left(\mathrm{gm} \mathrm{gm}^{-1}\right)$, and horizontal wind speed $\left(\mathrm{m} \mathrm{sec}^{-1}\right)$ at equally spaced vertical grid intervals. The grid interval used for the calculations was $200 \mathrm{~m}$.

The shear correction calculation derives the slope of the cloud, in response to the vertical shear of the horizontal wind, from the relationship given by Malkus (1952). The adjusted vertical velocity is taken as the vertical component of the sloping updraft.

Eqs. (1)-(7) were coded for a General Electric 265 time-sharing computer system. The advent of a com- 


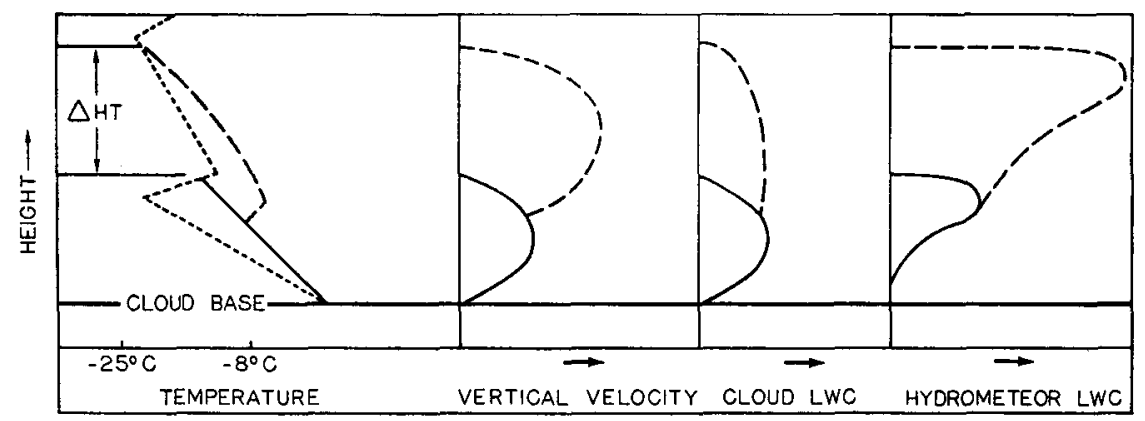

Fig. 3. Steady-state model output. The dotted line represents the environmental temperature sounding, $\Delta H t$ being the difference between the calculated seeded and non-seeded cloud top. The solid and dashed lines in the profiles represent the non-seeded and seeded calculations, respectively. The model also calculates the total precipitation duration of precipitation for the seeded and non-seeded cases.

puter time-sharing made possible the use of the numerical model as a real-time tool in the field. The General Electric system can be installed in virtually any location which has telephone service. The calculation time for a cloud of approximately $10-\mathrm{km}$ depth is $8 \mathrm{sec}$. Including input and output time, six cloud calculations can be performed in $\sim 40 \mathrm{~min}$ at a cost of approximately $\$ 10$.

Fig. 3 shows a schematic representation of the type of output desired from the model. This is the type of sounding which produces the ideal clouds for modification tests. The inversion is capping natural clouds before they can reach their freezing temperature. The introduction of seeding material allows the cloud to freeze below the inversion. The extra energy derived from the freezing allows the treated cloud to break through the inversion and grow several thousand feet higher than the natural cloud would have grown. The profiles of vertical velocity and liquid water content are those which would have been calculated from a sounding such as the one shown on the left. It can be seen that the seeding would increase the total precipitation (the integral of the $Q_{h}$ profile) as well as the cloud top height. Since mixing is the principal destructive force in isolated cumuli, a cloud smaller than the one used in this calculation would have topped out below the $-8 \mathrm{C}$ level, and seeding would not have been able to induce freezing. Similarly, a large cloud would have pierced the inversion and grown up to its natural freezing level. Introduction of seeding material would have simply caused freezing to occur at the $-8 \mathrm{C}$ level instead of at the $-25 \mathrm{C}$ level. It can be shown that the early freezing would not materially change the maximum height reached by the cloud, in spite of alterations of the microphysics.

\section{Analysis and results}

The analysis of the data started with the construction of time-height cross sections of the radar return (average "core" values), visual cloud top heights, and notes that were collected during the tests. Twenty-one cross sections, representing 10 seeded clouds and 11 controls, were constructed. Radar return, however, is not a direct measure of the clouds' water content.

A computer program, written at the Pennslyvania State University, was utilized to convert $P_{r}$ into the radar reflectivity factor $Z$, and ultimately into rainfall rate $R$. The pertinent equations for the calculation are given by Battan (1959), i.e.,

$$
P_{r}=\left(C / r^{2}\right) Z,
$$

where $C$ is the radar constant for the Nike-Ajax, $r$ the range to the target, and

$$
Z=200 R^{1.6}
$$

where $R$ is rainfall rate $\left(\mathrm{mm} \mathrm{hr}^{-1}\right)$.

Jones et al. (1968) showed that seeded clouds in Flagstaff may tend to have a drop-size distribution characterized by many more small drops and fewer large drops than the distribution for natural clouds. This is to be anticipated from consideration of the microphysics effects of the seeding. The $Z$ vs $R$ relationship [Eq. (9)] used in the data reduction was derived for "average" convective conditions. Since the radar reflectivity factor is proportional to $D^{6}$, while rainfall is proportional to only $D^{3}$, the use of the "average" $Z$ vs $R$ relationship in light of Jones' results might tend to overestimate the rainfall rate in the control clouds (few large drops), while underestimating the rainfall rate in the seeded clouds (many small drops). Evaporation below cloud base will tend to remove slightly more of the rain in the seeded case before the rain actually reaches the ground. This effect would somewhat cancel the relative underestimating of seeded precipitation. Here we are looking for gross effects and so will not consider such details further. For more quantitative studies in the future, with more detailed models, the rainfall observations should include ascertaining the raindrop size distribution for the particular case, and relating this to model predictions. 
TABLE 1a. Summary of observed data.

\begin{tabular}{|c|c|c|c|c|c|c|c|c|c|c|c|c|c|}
\hline Parameter & $\begin{array}{c}\text { Control } \\
\text { (C) or } \\
\text { Seeded (S) }\end{array}$ & $\begin{array}{l}18 \\
\text { July }\end{array}$ & $\begin{array}{c}19 \\
\text { July }\end{array}$ & $\stackrel{21}{\text { July }}$ & $\begin{array}{c}24 \\
\text { July }\end{array}$ & $\begin{array}{c}25 \\
\text { July }\end{array}$ & $\begin{array}{l}\text { Date } \\
29 \\
\text { July }\end{array}$ & $\begin{array}{c}\text { (1967) } \\
31 \\
\text { July }\end{array}$ & $\stackrel{2}{\text { August }}$ & $\stackrel{3}{\text { August }}$ & $\stackrel{9}{\text { August }}$ & $\begin{array}{c}10 \\
\text { August }\end{array}$ & Average \\
\hline \multirow[t]{2}{*}{ Radius (km) } & $\mathrm{C}$ & 1.4 & 2.0 & 1.4 & 1.6 & 0.9 & 0.4 & 2.4 & 0.9 & $*$ & 1.4 & 1.2 & 1.3 \\
\hline & $\mathrm{s}$ & 1.5 & 1.3 & 1.4 & 2.0 & 1.0 & 0.8 & 1.7 & 1.2 & 1.3 & $*$ & 0.5 & 1.3 \\
\hline \multirow{2}{*}{$\begin{array}{l}3-\mathrm{cm} \text { radar top } \\
(1000 \mathrm{ft})\end{array}$} & $\mathrm{C}$ & $* *$ & $* *$ & 28.0 & 26.0 & 26.5 & 17.5 & 29.0 & 25.0 & $*$ & 28.5 & 24.5 & 25.6 \\
\hline & $\mathrm{s}$ & 24.0 & 19.5 & 32.5 & 39.3 & 25.5 & 26.0 & 43.5 & 30.5 & 35.0 & $*$ & 28.8 & 31.5 \\
\hline \multirow{2}{*}{$\begin{array}{l}\text { Visual top } \\
\quad(1000 \mathrm{ft})\end{array}$} & C & 20.8 & 18.0 & 30.0 & 27.2 & 28.0 & 18.0 & 30.3 & 26.0 & $*$ & 30.2 & 27.0 & 25.6 \\
\hline & $\mathrm{s}$ & 25.0 & 20.0 & 34.5 & 42.2 & 36.0 & 27.2 & 44.0 & 33.0 & 39.5 & $*$ & 32.0 & 33.5 \\
\hline \multirow{2}{*}{$\begin{array}{l}\text { Start of cloud } \\
\text { (MST) }\end{array}$} & $\mathrm{C}$ & 1550 & 1147 & 1114 & 1207 & 1134 & 1143 & 1157 & 1029 & $*$ & 1110 & 1215 & 1201 \\
\hline & $\mathrm{s}$ & 1510 & 1042 & 1300 & 1018 & 1245 & 1053 & 1319 & 1118 & 1148 & * & 1115 & 1203 \\
\hline \multirow{2}{*}{$\begin{array}{l}\text { Duration of rain } \\
\text { (min) }\end{array}$} & $\mathrm{c}$ & $* *$ & $* *$ & 27 & 31 & 21 & 10 & 41 & 22 & $*$ & 36 & 21 & 26 \\
\hline & $\mathrm{s}$ & 14 & 26 & 31 & 61 & 52 & 32 & 43 & 28 & 45 & $*$ & 34 & 36 \\
\hline \multirow{2}{*}{$\begin{array}{l}\text { Total rain } \\
\quad(\mathrm{mm})\end{array}$} & $\mathrm{C}$ & $* *$ & $* *$ & 3.14 & 0.51 & 0.79 & 0.03 & 7.57 & 0.86 & $*$ & 7.42 & 0.74 & 2.63 \\
\hline & $\mathrm{s}$ & 0.05 & 0.11 & 6.50 & 4.02 & 4.59 & 9.23 & 8.73 & 3.77 & 7.34 & * & 1.90 & 4.63 \\
\hline \multirow{2}{*}{$\begin{array}{l}\text { Height of first } 3-\mathrm{cm} \\
\text { echo }(1000 \mathrm{ft})\end{array}$} & $\mathrm{C}$ & $* *$ & $* *$ & 21.0 & 18.0 & 21.5 & 13.5 & 22.0 & 20.5 & $*$ & 22.0 & 20.0 & 20.0 \\
\hline & $\mathrm{s}$ & 19.0 & 16.1 & 22.0 & 20.2 & 22.1 & 19.2 & 22.5 & 23.0 & 26.2 & $*$ & 20.5 & 21.5 \\
\hline
\end{tabular}

* No companion test cloud.

** No 3-cm echo observed.

Table 1 contains a summary of the most important features of the time-height cross sections. It can be seen that the randomization was successful in removing any strong bias in the size selection; the average radius of seeded and control clouds was the same. The average time of day of the start of the seeding was also almost identical to the start of the mock seeding.

Using all the data, the seeded clouds had significantly higher visual tops $(7900 \mathrm{ft})$, radar tops $(5900 \mathrm{ft})$, durations $(10 \mathrm{~min})$, and rainfall $(2.00 \mathrm{~mm})$. The respective percentage increases, assuming 13,000-ft cloud bases, were $63,47,39$ and 76 . The significance of the increases, using the student $t$-test and assuming perfect randomization, were, respectively, $99 \%, 96 \%, 92 \%$ and $81 \%$. Since the randomization was not absolutely rigorous during the first half of the program, one cannot give a completely valid significance level to the average increases.

It is here worth considering the amount of bias that might have been introduced since selection of the second cloud was not rigorously randomized on the first five days. In these five cases, one involved the selection of a seeded cloud which was identical in size to the control cloud, in three cases the seeded cloud was somewhat larger (by $0.1,0.4$ and $0.1 \mathrm{~km}$ radius) than the control,

TABLE 1b. Average increases, seeding cases compared to control cases.

\begin{tabular}{lcccc}
\hline & $\begin{array}{c}+7,900 \mathrm{ft} \\
(+63 \% \\
\text { consid- } \\
\text { ering } \\
\text { bases at } \\
13,000 \mathrm{ft})\end{array}$ & $\begin{array}{c}+5,900 \mathrm{ft} \\
(+47 \% \\
\text { consid- } \\
\text { ering } \\
\text { bases at } \\
13,000 \mathrm{ft})\end{array}$ & $\begin{array}{c}+10 \mathrm{~min} \\
(+39 \%)\end{array}$ & $\begin{array}{l}2.00 \mathrm{~mm} \\
(+76 \%)\end{array}$ \\
\hline $\begin{array}{c}\text { Increase } \\
\begin{array}{c}\text { (assuming valid } \\
\text { randomization) }\end{array}\end{array}$ & $99 \%$ & $96 \%$ & $92 \%$ & $81 \%$ \\
\hline
\end{tabular}

and in one case the seeded cloud was substantially smaller (by $0.7 \mathrm{~km}$ ) than the control. There is no obvious evidence of bias here, at least on the basis of measured radii. One must still accept the possibility that the observer used some such criterion as cloud "firmness" to bias unconsciously the selection in favor of seeded clouds, but we deem this possibility to be extremely remote.

The observational data can be further examined. If one uses only the cases for which the data were paired (7 pairs for radar tops, duration and precipitation; 9 days for visual tops), the seeded and control data should come from more comparable conditions than for the averages on Table 1 . Table 2 shows only the increases that occurred on the days in which cloud pairs were observed.

If the environmental condition and the initial radius are the main factors in determining cloud growth, with the seeding representing the one test variable, then differences between a seeded and control pair would be significant if these two main factors were the same for both clouds. For the pair of clouds on one day, the environment tends to be rather similar. The cloud selector tried to pick two clouds with comparable radii, but this was often not possible as shown in the top lines of Table 1. Nevertheless, Table 1 does show that for every pair there was an increase in height, precipitation and duration for the seeded cloud compared to the unseeded. It thus appears that the effects of changes in cloud radii were small compared to the changes produced by seed-

TABLE 2. Seeding increases for paired data.

\begin{tabular}{lcccc}
\hline & Visual tops & Radar tops & Duration & Rainfall \\
\hline Increase & $7600 \mathrm{ft}$ & $8500 \mathrm{ft}$ & $15 \mathrm{~min}$ & $3.58 \mathrm{~mm}$ \\
$t$-test & $98 \%$ & $99 \%$ & $98 \%$ & $89 \%$ \\
\hline
\end{tabular}


ing. The significance of these sets of pairs may be estimated by another form of student's $t$-test, using only the differences (seeded minus control) quantities. With this method, only the height increases are found to be significant $(>85 \%)$; radar tops at $97 \%$, and visual tops at $89 \%$.

The above results are observations, not related to the numerical model except that the inputs to the model gave hints as to how to select seeded and control clouds from truly comparable populations, and that the model helped in the selection of clouds expected to show big effects from seeding. The rest of the analysis now involves the computer model. The model was run on each day's data, using a sounding representative of the time of the tests, and the cloud base radius measured by the C-180 on its initial pass. The sounding was usually a conglomerate of the aircraft sounding and a radiosonde sounding taken a few hours before the tests.

Table 3 shows the constants used in the parameterization. It should be noted that it was necessary to abandon the standard 0.2 for the constant in the mixing rate in favor of 0.15 . It was found, with the standard mixing rate, that the calculated cloud top heights were consistently below the observed heights. In considering the validity of the model, it should be noted that the value of 0.15 was the first "guess" away from 0.2. It was not derived mathematically by comparing predictions and observations for many different values.

The coefficients in the cloud microphysics parameterization represent slight modifications to the suggestions of Kessler et al. (1962-1964). The conversion parameter was increased after freezing in order to simulate prefer-
TABLE 3. Parameterization constants.

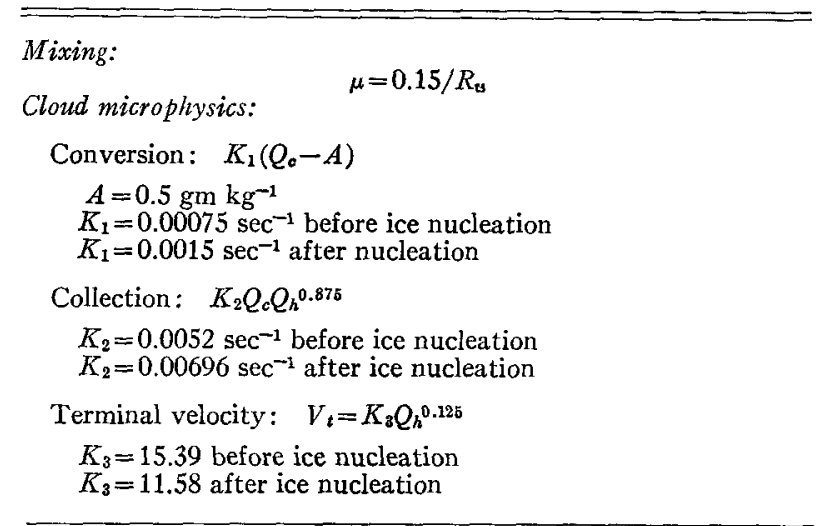

ential freezing of large drops and subsequent diffusional growth of these ice particles in the presence of the liquid cloud water. The collection and terminal velocity parameters were altered in response to Jones' data on the difference the drop-size distributions in seeded and natural clouds. These modifications were based on the physical picture of the precipitation mechanisms and were incorporated into the model without regard for the field observations. Subsequent sensitivity studies have shown that large variations in $K_{1}, K_{2}$ and $K_{3}$ make practically no difference in the resulting height, precipitation and duration predictions.

Table 4 gives a summary of the computer model calculations. The skill and error in the predictions of radar top height, precipitation, and duration can be seen in Figs. 4-6.

TABLE 4. Summary of computer model calculations.

\begin{tabular}{|c|c|c|c|c|c|c|c|c|c|c|c|c|c|c|}
\hline \multirow[b]{2}{*}{ Date } & \multirow[b]{2}{*}{$\mathrm{C} / \mathrm{s}$} & \multirow[b]{2}{*}{$\underset{(\mathrm{km})}{\text { Radius }}$} & \multirow[b]{2}{*}{$\begin{array}{l}\text { Height } \\
(1000 \\
\text { ft })\end{array}$} & \multirow[b]{2}{*}{$\begin{array}{c}\text { If seeded } \\
\text { Precip- } \\
\text { itation } \\
(\mathrm{mm})\end{array}$} & \multicolumn{2}{|c|}{ Predicted } & \multirow[b]{2}{*}{$\begin{array}{c}\text { If control } \\
\text { Precip- } \\
\text { itation } \\
(\mathrm{mm})\end{array}$} & \multirow[b]{2}{*}{$\begin{array}{c}\text { Dura- } \\
\text { tion } \\
\text { (min) }\end{array}$} & \multicolumn{3}{|c|}{ Observed } & \multicolumn{3}{|c|}{ Prediction error } \\
\hline & & & & & $\begin{array}{l}\text { Dura- } \\
\text { tion } \\
\text { (min) }\end{array}$ & $\begin{array}{l}\text { Height } \\
(1000 \\
\text { ft })\end{array}$ & & & $\begin{array}{c}\text { Height } \\
(1000 \\
\mathrm{ft})\end{array}$ & $\begin{array}{l}\text { Precip- } \\
\text { itation } \\
(\mathrm{mm})\end{array}$ & $\begin{array}{l}\text { Dura- } \\
\text { tion } \\
\text { (min) }\end{array}$ & $\begin{array}{c}\text { Height } \\
(1000 \\
\mathrm{ft})\end{array}$ & $\begin{array}{l}\text { iction error } \\
\text { Precip- } \\
\text { itation } \\
\text { (mm) }\end{array}$ & $\begin{array}{l}\text { Dura- } \\
\text { tion } \\
\text { (min) }\end{array}$ \\
\hline \multirow[t]{2}{*}{18 July } & C & 1.4 & 21.3 & 0.24 & 9 & 20.7 & 0.14 & 9 & $20.3^{*}$ & ** & $*$ & +0.4 & +0.14 & $* *$ \\
\hline & S & 1.5 & 22.0 & 0.36 & 9 & 21.3 & 0.20 & 10 & 24.0 & 0.05 & 14 & 2.0 & +0.31 & -5 \\
\hline \multirow[t]{2}{*}{19 July } & $\mathrm{C}$ & 2.0 & 24.6 & 0.87 & 9 & 22.6 & 0.16 & 10 & $17.5^{*}$ & $* *$ & $*$ & 5.1 & +0.16 & $*$ \\
\hline & $\mathrm{S}$ & 1.3 & 23.3 & 0.38 & 9 & 22.0 & 0.09 & 9 & 18.5 & 0.11 & 26 & 3.8 & +0.27 & -17 \\
\hline \multirow[t]{2}{*}{21 July } & $\mathrm{c}$ & 1.4 & 37.1 & 7.71 & 19 & 27.9 & 3.51 & 11 & 28.0 & 3.14 & 27 & 0.1 & +0.37 & -16 \\
\hline & $S$ & 1.4 & 37.1 & 7.71 & 19 & 27.9 & 3.51 & 11 & 32.5 & 6.50 & 31 & 4.6 & +1.21 & -12 \\
\hline \multirow[t]{2}{*}{24 July } & C & 1.6 & 38.0 & 16.94 & 21 & 26.2 & 6.19 & 12 & 26.0 & 0.51 & 31 & $+\quad 0.2$ & +5.68 & -19 \\
\hline & $S$ & 2.0 & 41.3 & 19.89 & 24 & 27.6 & 7.18 & 17 & 39.3 & 4.02 & 61 & +2.0 & +15.87 & -37 \\
\hline \multirow[t]{2}{*}{$25 \mathrm{July}$} & $c$ & 0.9 & 30.2 & 6.23 & 15 & 23.0 & 1.21 & 9 & 26.5 & 0.79 & 21 & -3.5 & +0.42 & -12 \\
\hline & $\mathrm{S}$ & 1.0 & 32.1 & 6.60 & 16 & 27.6 & 3.30 & 13 & 35.5 & 4.59 & 52 & $-\quad 3.4$ & +2.01 & -36 \\
\hline \multirow[t]{2}{*}{29 July } & c & 0.4 & 28.5 & 24.08 & 12 & 20.0 & 2.58 & 6 & 17.5 & 0.03 & 10 & +2.5 & +2.55 & -4 \\
\hline & $S$ & 0.8 & 29.8 & 9.54 & 15 & 22.6 & 3.69 & 9 & 26.0 & 9.23 & 32 & $\begin{array}{r}3.8 \\
+\quad 3\end{array}$ & +0.31 & -17 \\
\hline \multirow[t]{2}{*}{$31 \mathrm{July}$} & C & 2.4 & 40.7 & 30.47 & 23 & 26.2 & 12.72 & 10 & 29.0 & 7.57 & 41 & $-\quad 2.8$ & +5.15 & -31 \\
\hline & $\mathrm{S}$ & 1.7 & 37.7 & 20.38 & 21 & 22.0 & 3.02 & 9 & 43.5 & 8.73 & 43 & $-\quad 5.8$ & +11.65 & -22 \\
\hline \multirow[t]{3}{*}{2 August } & C & 0.91 & 31.8 & 8.46 & 16 & 23.3 & 2.48 & 9 & 25.0 & 0.86 & 22 & $-\quad 1.7$ & +1.62 & -31 \\
\hline & C & 0.95 & 31.8 & 8.51 & 16 & 25.3 & 4.56 & 10 & 23.8 & $* *$ & $* *$ & $+\quad 1.5$ & $\begin{array}{r}+4.56 \\
\end{array}$ & $* * *$ \\
\hline & $S$ & 1.2 & 32.1 & 7.26 & 16 & 27.6 & 3.74 & 12 & 30.5 & 3.77 & 28 & +1.6 & +3.49 & -12 \\
\hline 3 August & $S$ & 1.3 & 33.4 & 9.74 & 17 & 33.4 & 9.88 & 17 & 35.0 & 7.34 & 45 & -1.6 & +2.40 & -28 \\
\hline 9 August & C & 1.4 & 35.8 & 9.29 & 19 & 35.1 & 8.36 & 19 & 28.5 & 7.42 & 36 & +6.6 & +0.94 & -17 \\
\hline \multirow[t]{2}{*}{10 August } & C & 1.2 & 34.8 & 9.44 & 18 & 27.5 & 1.11 & 10 & 24.5 & 0.74 & 21 & +3.0 & +0.37 & -11 \\
\hline & $\mathrm{S}$ & 0.5 & 24.3 & 2.21 & 10 & 21.6 & 0.68 & 9 & 28.8 & 1.90 & 34 & -4.5 & +0.31 & -24 \\
\hline Average & & 1.3 & 31.8 & 9.81 & 16 & 25.3 & 3.73 & 11 & \multicolumn{3}{|c|}{ See Table 1} & +462 & +2.81 & -19 \\
\hline
\end{tabular}

* When no radar top, use visual top minus $500 \mathrm{ft}$ 


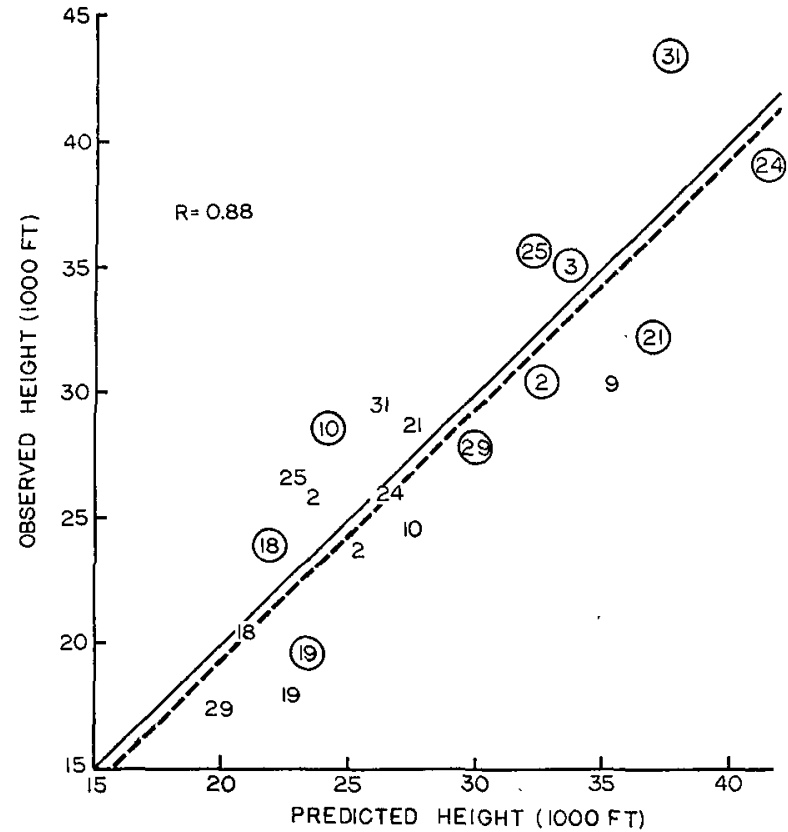

Fig. 4. Scatter diagram of observed vs predicted cloud top height. The number gives the days on which the observation was taken ( $<10$ was in August, $>18$ was in July). The enclosed numbers represent seeded cases. The solid line is a $1: 1$ fit, the dashed line the best fit.

To show validity of the height increase from seeding, 1) the model is developed with control cloud data and its predictive accuracy found, 2) the model is then used to estimate the height of each seeded cloud if the cloud

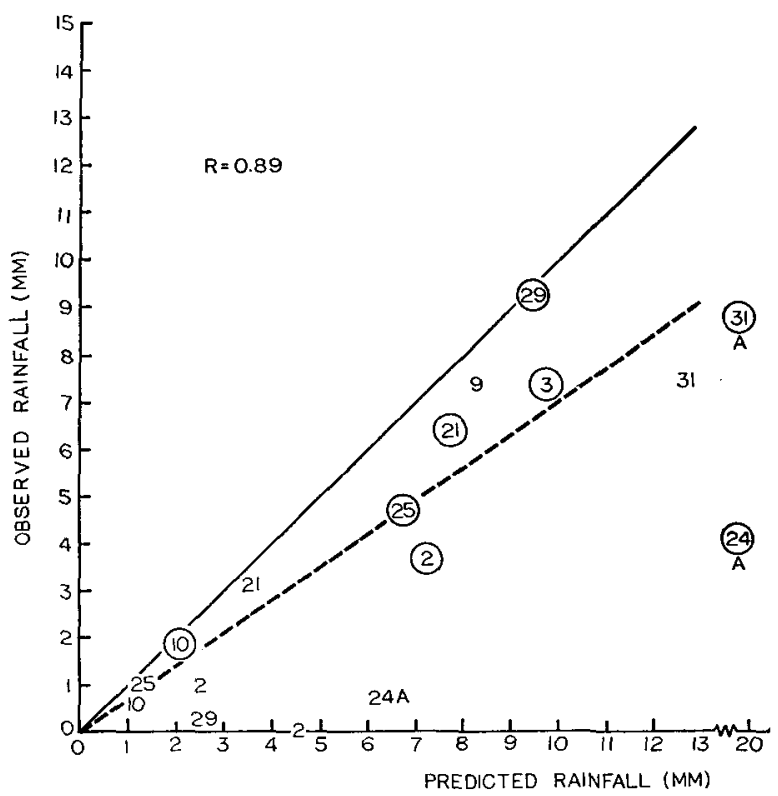

FIG, 5. Scatter diagram of observed radar rainfall vs predicted rainfall, with symbols the same as in Fig. 4. The correlation coefficient was calculated, not including the points labeled ' $A$ ' (see text for details). had not been seeded, 3) the estimated increase is found from "observed height seeded minus computed height unseeded," and 4) the validity of such increases is found with the $t$-test which takes account of the predictive inaccuracies. We take Fig. 4 as evidence of handling item 1). The control cloud points do cluster around the 1:1 line, which is a reasonable best fit. The prediction error has a mean of $1020 \mathrm{ft}$ and a standard deviation of $3000 \mathrm{ft}$. Considering the range of heights over which the calculations are applied, e.g., 15,000-45,000 ft, the agreement is quite satisfactory. Then following items 2 ) and 3), the seeding increases for the 10 observed cases are: $+2.7,-3.5,+4.6,+11.7,+7.9,+3.4$, $+21.5,+2.9,+1.6$ and +7.2 thousand feet. The mean is $6000 \mathrm{ft}$, and the standard deviation $6450 \mathrm{ft}$. Then, item 4 ), by the $t$-test, gives the significance of the increases as $96 \%$. Comparable arguments can be made for the rainfall and duration increases. These are not presented here primarily because questions arise as to which lines have statistical validity as the mathematical best fits.

The "best estimate" of cloud development and seeding effects comes from the best-fit lines on Figs. 4-6. These three scatter diagrams show that the scatter of points is not large, relative to the best-fit lines. Note that these lines fit both the seeded and control data rather well. The best-fit line for the height predictions of Fig. 4 can be taken as the line parallel to the $45^{\circ}$ line, and $462 \mathrm{ft}$ higher. For the accuracy desired here, the $462 \mathrm{ft}$ can be neglected. The correlation coefficient is $R=0.88$ and the rms error $3341 \mathrm{ft}$. For Figs. 5 and 6 , the correlation coefficients are $R=0.76$ and 0.89 , respectively, around the linear regression lines. The "eyeball" best-fit lines are plotted on Figs. 5 and 6 , constrained to go through the origins. The scatter appears to increase with the distance from the origin.

Fig. 5 shows the relationship between predicted and observed rainfall. Attention is first drawn to the three poor points (31 July seeded, and 24 July seeded and control). On these days, the lapse rate was practically moist adiabatic through a deep layer. Under such conditions, the cloud never gets much positive buoyancy and, consequently, never attains a high vertical velocity. On 24 and 31 July, the vertical velocity was calculated at a constant $5-7 \mathrm{~m} \mathrm{sec}^{-1}$ throughout the cloud depth. As the hydrometeor liquid water content builds, the terminal velocity rapidly approaches its limiting value. With the constants of parameterization used in the calculations, this limiting terminal velocity is approximately $7 \mathrm{~m} \mathrm{sec}^{-1}$. If the terminal and vertical velocities approach equality, the hydrometeors do not fall through the cloud but are suspended in the updraft until they drag the updraft down. While the hydrometeors are suspended, they collect cloud water continuously and ultimately collect copious amounts of precipitation. In a real cloud, the water loading will drag the vertical velocity sufficiently to allow the water to fall out in surges. In the steady-state model, however, the vertical 
velocity cannot change with time, the hydrometeors cannot fall out, and the water content continues to increase. It can be seen in Table 4 that the calculated rainfall for the 24th and 31st of July is 2-3 times the amount calculated for any other day with the exception of the seeded prediction for the small cloud on 29 July (a case of high-level stability leading to the same effect). The conclusion one must draw from this discussion is that the steady-state model has its limitations in applicability. One such limitation is in conjunction with clouds in which the steady-state assumption is particularly poor. The 24th and 31st were apparently cases where the present model should not be applied to predict rainfall.

The remainder of Fig. 5 shows that the model has some value for predicting total rainfall when applied to most soundings. The correlation coefficient between predicted and observed rainfall, omitting the three poor points, was 0.89 . The slope of the best-fit line was 0.7 , indicating that the model is calculating approximately $44 \%$ more rain than is being observed. Most studies of radar-measured rainfall indicate that a radar measure of rainfall can be off easily by a factor of 2 . The radar inaccuracies are not meant to imply that the model calculations are right. The point to be made is that some improvements in rainfall measurements must be made so as to allow a better calibration of the cloud microphysics parameterization.

Fig. 6 shows the relationship between predicted and observed duration of rainfall at cloud base. The three control clouds for which no $3-\mathrm{cm}$ radar echo was observed are not entered on the figure. The correlation between predicted and observed duration, 0.76, indicates that the model has a fair degree of skill in predicting duration. The slope of the eyeball best-fit line through the origin $(\sim 2.2)$ is in qualitative agreement with the slope of the regression line for total rainfall. Predicting rainfall too high means predicting the hydrometeor velocity too high also, which corresponds to predicting duration too low.

In applying the steady-state model to a real, timedependent cloud, we have assumed the cloud decays and all the hydrometeors start falling through still air the moment the parcel reaches the peak altitude. Actually, the cloud carries on much longer than this, which probably accounts for a major part of the 2.2 slope correction factor for duration estimates.

From the scatter diagrams, we can say the best prediction would come from the following modification of the present computer model:

1) For height, use the model directly.

2) For precipitation, multiply the model prediction by 0.7 , and do not apply the calculation to cases with the environmental lapse rate close to the moist adiabatic.

3) For duration, multiply the model prediction by 2.2 .

The statistical validity of such predictions can be de-

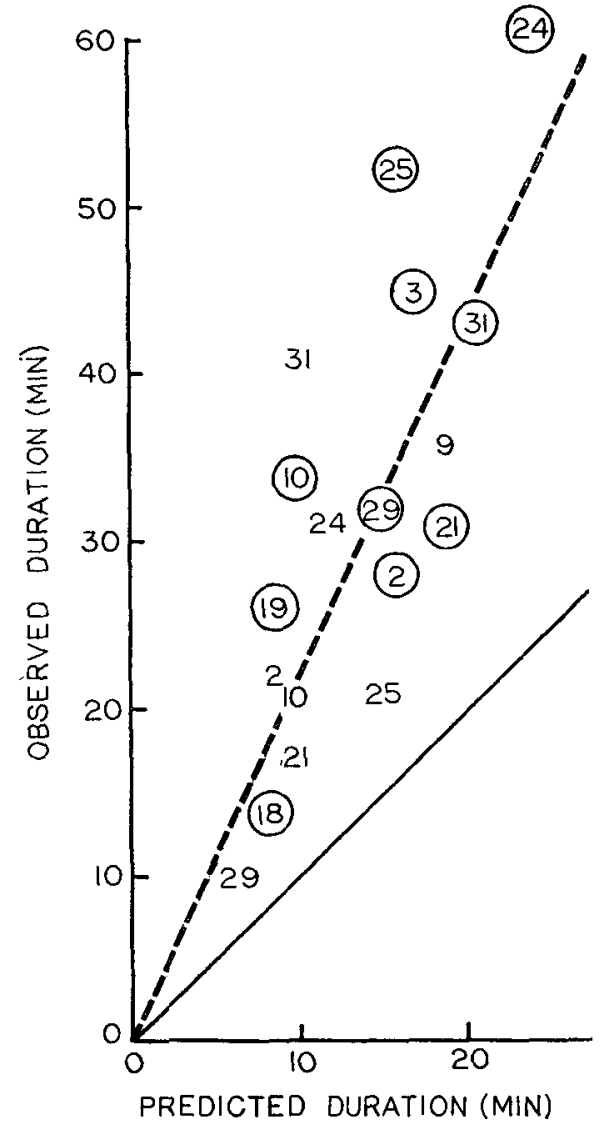

FIG. 6. Scatter diagram of observed vs predicted precipitation duration with symbols the same as in Fig. 4.

rived only from applying the above model to independent data, data not used in deriving the modifications.

The model can give some estimate of seeding effects for a particular cloud population. Note that the data were not stratified into seeded and control cases during the empirical testing and modifying of the model. We can use as an example the cloud population of the 21 cases shown on Table 4 . Table 4 shows the average computed height increase for the 21 cases is $6500 \mathrm{ft}(31,800$ $\mathrm{ft}$ if seeded vs $25,300 \mathrm{ft}$ if unseeded), while the rms prediction error is $3341 \mathrm{ft}$. For the best precipitation and duration estimates from Table 4, delete the 24 July and 31 July data for the reasons cited earlier. Then the precipitation increases $2.86 \mathrm{~mm}(2.99-6.98 \mathrm{~mm}$, with the 0.7 factor used) while duration increases $7 \mathrm{~min}$ (14 seeded, 11 unseeded, with the 2.2 factor used).

\section{Evaluation of the project and suggestions for the future}

We feel that there can be little argument with the conclusion that the seeding produced increased cloud top heights, rainfall amounts and duration. This is shown by examination of the observations alone, and 
by examination of the seeding cases with the model aiding in supplying control information. Comparable magnitudes for the increases are also found on the basis of model predictions for both seeding and control cases. The model seems satisfactory for the purposes for which it was used, and the particular type of seeding and randomized selection served the program as anticipated. The program could even derive significant results in cases where the first echo was natural.

The model exhibits some skill in calculating relative rainfall amounts and duration. With improved rainfall verification measurements, the cloud microphysics parameterization can be calibrated and the model calculations can be made to produce accurate absolute predictions.

The seeding procedure was performed with the objective of glaciating the total cloud. This is in line with the desire to gain as much thermodynamic benefit as possible from the seeding. This procedure required that enough seeding material be provided to ensure that virtually all of the liquid water colder than a certain temperature is transformed into ice. It ignores the potential benefit that could be derived from the optimum initiation of colloidal instability, in favor of increasing the cloud's depth and total water processing capability.

Whether the clouds were overseeded or not in 1967 cannot be ascertained from this brief look at the data. There is certainly no reason to believe the seeding was optimum. There is some suggestion of both underseeding and overseeding. The records show much larger increases when the seeding was performed with two generators rather than one, but it is felt this is the result of expected statistical variation with a very small number of cases. If a factor of 2 increase in seeding did increase the precipitation, then we were sometimes underseeding. However, we feel the likelihood is greater that there was often overseeding. The seeding rate per generator was $6 \mathrm{gm}$ of AgI per minute, so the total treatment was $\sim 120$ or $240 \mathrm{gm}$ per cloud.

The procedures developed for the project are simple and can be carried out on an operational basis. The modified computer model has been shown to have a high degree of skill in predicting cloud top heights and gives good qualitative prediction about total rainfall amounts and duration.

There were several instrumented aircraft penetrations through the test cloud in August. The ideas on which the seeding and the model are based can be partially verified or disproven by a thorough analysis of the aircraft data. Studies on this data will provide useful clues to be used in developing more optimum methods of seeding. Such seeding would involve deriving the required, but not necessarily the total possible, thermodynamic benefit from seeding, while retaining, somewhat, the colloidal instability benefit. The most effective seeding would no doubt require concentrations of nuclei and even types of nuclei to be varied in time and space in a complex manner. Operational considerations require that compromises be made for simplicity.

The project uncovered some flaws in the procedure, the principal one being the weakness of the rainfall measurement technique. There was not enough emphasis placed on this aspect of the data collection. The second flaw was in the aircraft sounding. The model predictions can only be as good as the sounding, and the sounding left much to be desired. In future tests, the aircraft sounding will have to be carried higher, since most of the clouds grew up above the level where the sounding was terminated. A better alternative to a higher aircraft sounding would be to include provisions for standard radiosonde soundings during the test period. The best time for the soundings would be immediately preceding and immediately following the tests.

The numerical model was found to be deficient in conditions where the sounding showed a moist adiabatic lapse through a deep layer. The deficiencies may be cleared up through a better calibration of the cloud microphysics parameterization. There is, however, the distinct possibility that a steady-state model cannot be used to calculate precipitation whenever the vertical velocity of the air and the terminal velocity of the hydrometeors are of the same magnitude. For these particular cases, it may be necessary to resort to a more time-consuming, time-dependent model.

The present model applies only to a rather limited selection of clouds. One basic difficulty is the assumption in the model that the cloud base diameter is constant. Often it grows larger than the initial value used in the model. This may be one significant contributor to the need for a 0.15 mixing coefficient to replace the 0.2 value used earlier. The base diameter depends on conditions below the base (the sounding, topography, heat sources) as well as on events aloft, so a model which ignores events below cloud base in Flagstaff clouds cannot be generally applicable. The constants in the cloud microphysics parameterization depend upon the dropsize distribution in the cloud, so these constants will probably have to be adjusted if the model is to be applied under different synoptic and/or environmental conditions. Future individual cumulus models will be directed first toward handling the simple isolated clouds of Flagstaff more accurately, and then handling more complex clouds and more varied environmental conditions.

Acknoreledgments. The field experiments and the main data reduction and evaluation were supported by the Bureau of Reclamation Project Skywater Contract with MRI, No. 14-06-D-5589. Much of the modeling development and some evaluation was handled at Pennsylvania State University (PSU) with joint support by the contract and an NSF grant to PSU. Larry G. Davis, working for MRI and PSU, played a key role in the setup and conduct of the program. J. I. Kelley, also of PSU, 
performed most of the data reduction and statistical evaluations. The field work, data reduction and evaluation have involved the efforts of many persons too numerous to mention here.

\section{REFERENCES}

Battan, L. J., 1959: Radar Meteorology. University of Chicago Press, $161 \mathrm{pp}$.

Davis, L. G., 1965: Alterations of buoyancy in cumuli. Ph.D. thesis, The Pennsylvania State University.

Hosler, C. L., L. G. Davis and D. R. Booker, 1963: Modification of convective systems by terrain with local relief of several hundred meters. Z. Angew. Math. Phys., 14, 410-419.

Jones, D. M. A., G. E. Stout and E. A. Mueller, 1968: Raindrop spectra for seeded and unseeded showers in Arizona. Proc. First Natl. Conf. Weather Modification, Albany, N. Y., 99-106.

Kessler, E., III, P. J. Feteris, E. A. Newberg and G. Wickham, 1962-1964: Relationship between tropical precipitation and kinematic cloud models. Prog. Repts. 1-5, The Travelers Research Center, Inc., Hartford, Conn., Contract DA-36-039SC89099. (Available from DDC, Alexandria, Va., as AD 286 737, AD 296 036, AD 402 766, AD 424 993, AD 437817 .)

Langmuir, I., 1948: The production of rain by a chain reaction in cumulus clouds at temperatures above freezing. $J$. Meteor., 5 , 175-181.

Malkus, J. S., 1952: Recent advances in the study of convective clouds and their interaction with the environment. Tellus, 4, No. 2, 71-87.

Simpson, J., R. H. Simpson, D. A. Andrews and M. A. Eaton, 1965: Experimental cumulus dynamics. Rev. Geophys., 3, $387-431$.

Stommel, H., 1947: Entrainment of air into a cumulus cloud. J. Meteor., 4, 91-94.

Weinstein, A. I., and L. G. Davis, 1968: A parameterized numerical model of cumulus convection. Rept. 11 to National Science Foundation under Grant GA-777 to the Dept. of Meteorology, Pennsylvania State University. (Available from CFSTI, Springfield, Va. as PB 179 389.) 